\title{
DESIGN OF A 50-KILOGRAM CAPACITY CAST IRON CRUCIBLE FURNACE USING LOCALLY AVAILABLE MATERIALS
}

\author{
Asibeluo, I. S , Ogwor O.E \\ ${ }^{1}$ Mechanical Engineering Department, Delta State Polytechnic, P.M.B 1030, Ogwashi-Uku, Delta State, Nigeria \\ ${ }^{2}$ Mechanical Engineering Department, Delta State Polytechnic, P.M.B 1030, Ogwashi-Uku, Delta State, Nigeria
}

\begin{abstract}
This research work focuses on the design of a 50-kilogram capacity Cast-iron crucible furnace that is fired with diesel fuel. The furnace drum has an overall combustion capacity of $0.1404 \mathrm{~m}^{3}$. It is fitted with a chimney to allow for the easy escape of combustion gases. The air blower discharge air into the furnace at the rate of $0.3 \mathrm{~m}^{3} / \mathrm{s}$ with an air/fuel ratio of 400:1. The castiron crucible furnace is designed to consume 4 gallons of diesel fuel with a rating of 139000kj/gallon which is required to completely melt 50-kilogram of cast iron over a period of 90min. The designed operation temperature range of the cast-iron crucible furnace is $1300^{\circ} \mathrm{C}$ to $1400^{\circ} \mathrm{C}$. The cost of the cast-iron crucible furnace is three hundred and forty-eight thousand naira (N348, 000.00).
\end{abstract}

Keywords: Furnace, Crucible, Cast Iron, Melting temperature, Efficiency

\section{INTRODUCTION}

Foundry deals with the melting of metals to their molten state, and eventually pouring the molten metal into a prepared mould to form a casting [8]. A crucible furnace, is a piece of equipment used in the foundry industry for melting metals for casting metallic wares such as; machines, machine parts and other related engineering materials. A cast iron crucible furnaces is therefore one meant for melting and casting of cast-iron products. On a general note, furnaces are also employed in the heat treatment of metals in order to influence their mechanical and physical properties.

The furnace is the most important equipment used in the foundry industry, which is an industry that uses logical methods for shaping metals. Almost all industries rely on castings products whose productions are impossible without the furnace. Examples of industries that depend on foundry industry are Automobile, Machine tools, Aerospace, Electrical, Plumbing, Communication etc[1].

The importance of the cast iron crucible furnace to the foundry industry as it affects industrial and technological development of any nation cannot be over emphasized, since many machine components are made of cast iron.

The development of the foundry industry in Nigeria has suffered several set-backs such as lack of stable electrical power supply [13], high cost of importation of foreign furnaces, raw materials etc. which had resulted to low production output[14], loss of man hours, high cost of production, and in most cases, loss of jobs occasioned by closure of most of the industries. There are about 160 foundries in Nigeria at different stages of life and death conditions and they meet less than $5 \%$ of Nigeria's demand for machine components and mechanical parts [2]. Most castings in Nigeria are imported [9]. The poor performance of the manufacturing sector in Nigeria is indicative of the low state of the foundry industry of which majority are small-medium scale enterprises with an unsubstantial total productive cost and input to the upper limit of only between 5-20 million naira [11],[14]. This is quite very low compared to that in the US where the [5] put the market value of the annual casting shipments at 28-30 billion US dollars produced by approximately 3,200 foundries. These myriad of problems therefore, necessitated this research work; "Design of a 50-Kilograpm Capacity Cast-Iron Crucible Furnace Using Locally Available Materials". The furnace is an efficient and reliable cast iron crucible furnace with operating temperature range of $1300^{\circ} \mathrm{c}$ to $1400^{\circ} \mathrm{c}$. It is designed to be constructed with locally available materials and to be fired with diesel fuel in order to tackle the dual problems of poor electrical power supply which has made it almost impossible for the foundry industry to thrive, and over-dependence on importation of foreign foundry furnaces which has led to high capital flight and its attendant economic backlash on the nation. This design has a lot of positive economic implications such as availability, maintainability, functionality etc. thus leading to comparative cost advantage over the imported ones.

\section{LITERATURE REVIEW}

A furnace is an equipment used for melting of metals for casting and heat treatment purposes. It derives its name from the Latin world "FORNEX" meaning oven. Iron melting in Nigeria dates back to the Nok culture of 2000 years ago in the Middle belt area of the country while on the Southern plains, bronze casting has been practiced by the Binis for over a thousand years [15]. Archaeologist have traced early iron works, blacksmith artifact and artistic castings to Ife and Igboukwu communities [7],[3]. 
The British colonial government in Nigeria set up engineering workshops at Ebute Metta, Enugu and Zaria to serve the railway system with each of the workshops having functioning foundry where castings were produced for needed spare parts [6]. The setting up of the first steel plant in Nigeria, NIGERSTEEL company Ltd Emene in Enugu in 1991 was credited to the government of the defunct Eastern region [11]. A field survey conducted in 1991 by the National Committee on Industrial Development Project reveals that, there are about fifty(50) foundries in Nigeria with a total installed capacity of 35,350 tonnes of cast iron; 1350 tonnes of steel and 4250 tonnes of nonferrous metals[15]. [15] reported that [4] revised above figures upwards by quoting a commissioned study of the National Agency for Science and Engineering Infrastructure which found that Nigeria has 60 fondries with a total installed capacity of 152,770 tonnes of castings per annum valued at $\$ 196.3$ million. [2] was also reported by [15] to have quoted recent NASENI and RMRDC report indicating that there are about 160 foundries in Nigeria at various levels of life or death conditions.

Diesel-fired furnaces are either directly fired where the products of combustion come in direct contact with the metal charge as in reverberatory furnace, or indirectly fired where the products of combustion do not come in contact with the metal charge, as in a crucible furnace.

In order to withstand the load that will be exerted on the furnace, knowledge of the maximum thermal load that it can withstand is important [10].

The operational safety conditions as well as the required rigidity and strength of all parts must be correctly adhered to. The word "safety" must be borne in mind whenever construction is going on in order to avoid accidents in the workshop either to other personnel or to oneself.

\section{MATERIAL SELECTION}

The choice of materials for the construction of the furnace was based on the following engineering requirements:

(a) Weldability: This is the ability of the material to be welded

(b) Toughness: This is the ability of the material to withstand shock and absorb energy due to impact.

(c) Fatigue: This is the ability of the material to withstand cyclic stresses.

(d) Ductility: This is the ability for the material to be drawn into wire.

(e) Durability

(f) Availabilty

The mild steel plate used for fabricating most components of the furnace is ductile, thus making it possible for it to be rolled, folded and bent without cracks or fractures.

The under listed materials were specified for the design of the diesel fired crucible furnace.

(i) Mild steel plate $(5 \mathrm{~mm})$

(ii) Flat bar ( $5 \mathrm{~mm}$ mild steel) (iii) Threaded rod (mild steel rod)

(iv) Plane bearing (cast iron)

(v) Bricks

\section{METHOD OF CONSTRUCTION}

The $50 \mathrm{~kg}$ cast-iron crucible furnace was designed majorly to melt cast iron. However, the $50 \mathrm{~kg}$ cast-iron crucible furnace can also be used to melt other metals such as aluminum whose melting temperatures falls within its designed operation temperature range of $1300^{\circ} \mathrm{C}$ to $1400^{\circ} \mathrm{C}$. Some of the equipment used in fabricating the various parts of the furnace are as follows:(a)Folding/rolling machine (b) Drilling machine (c)Welding machine (d)Cutting tools (e)Marking/Measuring tools etc. The major components of the 50kg Cast-iron crucible furnace are as follows:(i) The Furnace Drum (ii) The furnace cover (iii)The Air Blower (iv)Fire bricks (v) Nozzle (vi) Furnace Cover Opening/Closing Mechanism

\subsection{Fabrication of the Furnace drum}

The furnace drum was made from a mild steel plate of $5 \mathrm{~mm}$ thickness by folding the mild steel plate into a cylindrical shape of $800 \mathrm{~mm}$ diameter with the aid of a rolling/folding machine. A circular mild steel plate of diameter $800 \mathrm{~mm}$ was cut using a cutting machine and subsequently welded to the bottom of the folded drum with the aid of an arc welding machine. See fig1.

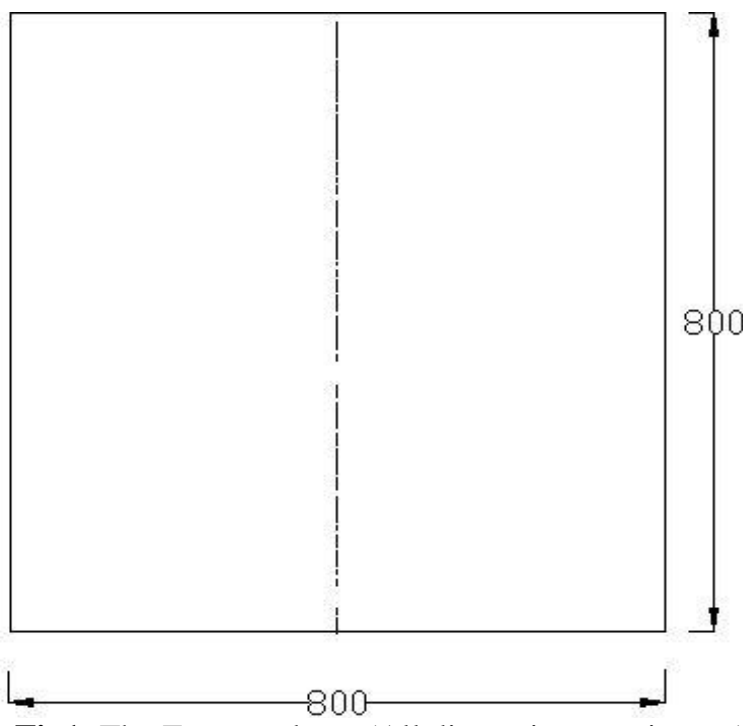

Fig1: The Furnace drum (All dimensions are in $\mathrm{mm}$ )

\subsection{Fabrication of the Furnace Cover}

The cover was made from a $5 \mathrm{~mm}$ mild steel plate. The mild steel plate was cut with oxyacetylene flame and thereafter welded with an arc welding machine using gauge 12 electrodes. The cover was impregnated/ filled with a refractory mixture comprising of sodium silicate, kaolin, sawdust and water to prevent or reduce the amount of heat loss. In order to firmly secure the insulating materials to the cover, pieces of rods were welded underneath the bottom part of the cover to hold the refractory mixture. See fig 2. 




Fig 2: The Furnace Cover (All dimensions are in $\mathrm{mm}$ )

\subsection{Lining the Furnace Wall with Bricks}

The inner surface of the furnace drum was lined round with a single layer of bricks of about $115 \mathrm{~mm}$ thickness using the refractory mixture comprising of sodium silicate, kaolin, sawdust and water as a binder to fill the spaces in between bricks in order for them to hold firmly together. The base of the furnace was lined with double layer of bricks of about $230 \mathrm{~mm}$ thickness using the same mixture of kaolin, sodium silicate, saw dust with water as binder. See fig3 and fig 4.



Fig 3: A Fire Brick (All dimensions are in $\mathrm{mm}$ )



Fig4: Furnace Wall Lined With Bricks (All dimensions are in $\mathrm{mm}$ )

\subsection{Fabrication of the Furnace Cover- \\ Opening/Closing Mechanism}

The furnace cover-opening/closing mechanism was made of a mild steel flat bar, mild steel rod and a threaded rod. The mild steel flat bar was cut into five equal parts of appropriate dimensions and welded together to form an open loop as shown in fig5, with the open side of the loop being equal to the diameter of the furnace cover. See fig 5.

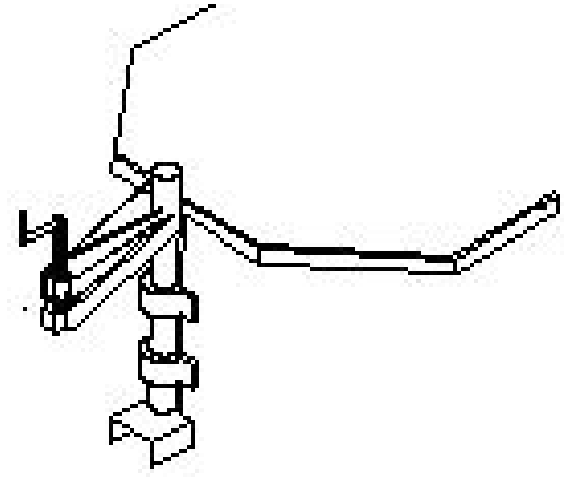

Fig5: Furnace Cover's Opening/Closing Mechanism (All dimensions are in $\mathrm{mm}$ )

\subsection{Fabrication of the Nozzle}

The nozzle was made from a mild steel cylindrical solid rod of length $350 \mathrm{~mm}$ and diameter of $180 \mathrm{~mm}$. A tapered hole was bored through the cylindrical solid rod with the larger end having a diameter $120 \mathrm{~mm}$ to serve as the inlet passage for air flowing from the air blower and the smaller end of diameter $35 \mathrm{~mm}$ to serve as the outlet passage for the supply of air for combustion in the furnace. The boring was done with a lathe machine. See fig 6.

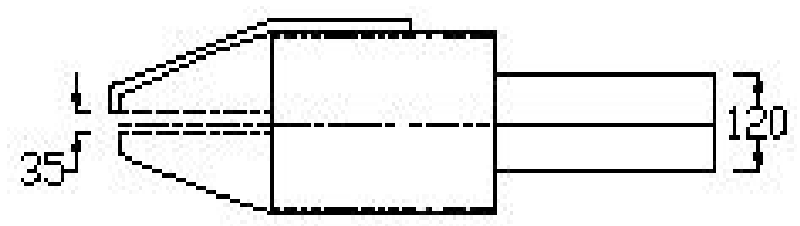

Fig6: Nozzle (All dimensions are in $\mathrm{mm}$ )

\subsection{Fabrication of the Diesel tank}

The diesel tank was made from a mild steel plate of $2 \mathrm{~mm}$ thickness. Five equal rectangular shaped pieces with dimensions of $800 \mathrm{~mm}$ by $600 \mathrm{~mm}$ were cut out of the mild steel plate with the aid of a cutting machine and thereafter welded together to form a cuboid-shaped structure with dimensions of $800 \mathrm{~mm} \times 600 \mathrm{~mm}$ x $600 \mathrm{~mm}$. Another piece of dimension $900 \mathrm{~mm}$ by $700 \mathrm{~mm}$ was cut out of the mild steel plate. The sides were folded by $1 \mathrm{~mm}$ to form the cover of the tank. Lastly a hole of about $80 \mathrm{~mm}$ diameter was bored at the base of the tank on one side and a pipe of about $12 \mathrm{~mm}$ diameter was welded to it, to serve as fuel supply line to the furnace. See fig 7.



Fig7: Fuel Tank (All dimensions are in $\mathrm{mm}$ ) 


\subsection{Assembling of Parts}

After all the parts were fabricated, two bearings were then welded to the body of the drum at one side. The next step was coupling the furnace cover-opening/closing mechanism to the two bearings. Thereafter, the furnace cover itself was then joined to the cover-opening/closing mechanism. The nozzle was at this point welded to the furnace drum. The air blower which was bought already made was subsequently connected to the nozzle. Lastly the pipe from the diesel fuel tank was linked to the furnace. See fig 8 .

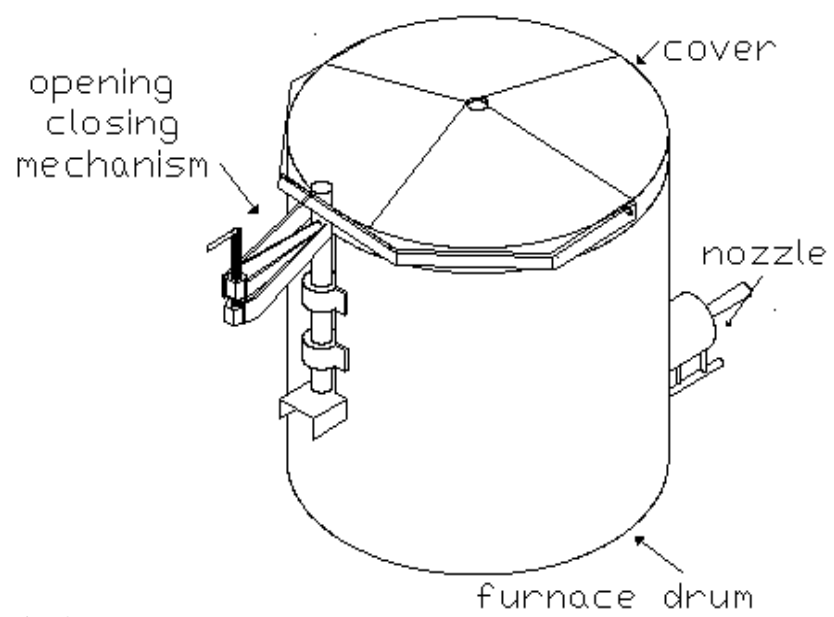

Fig 8: Assembly Drawing of the Cast-Iron crucible Furnace (All dimensions are in $\mathrm{mm}$ )
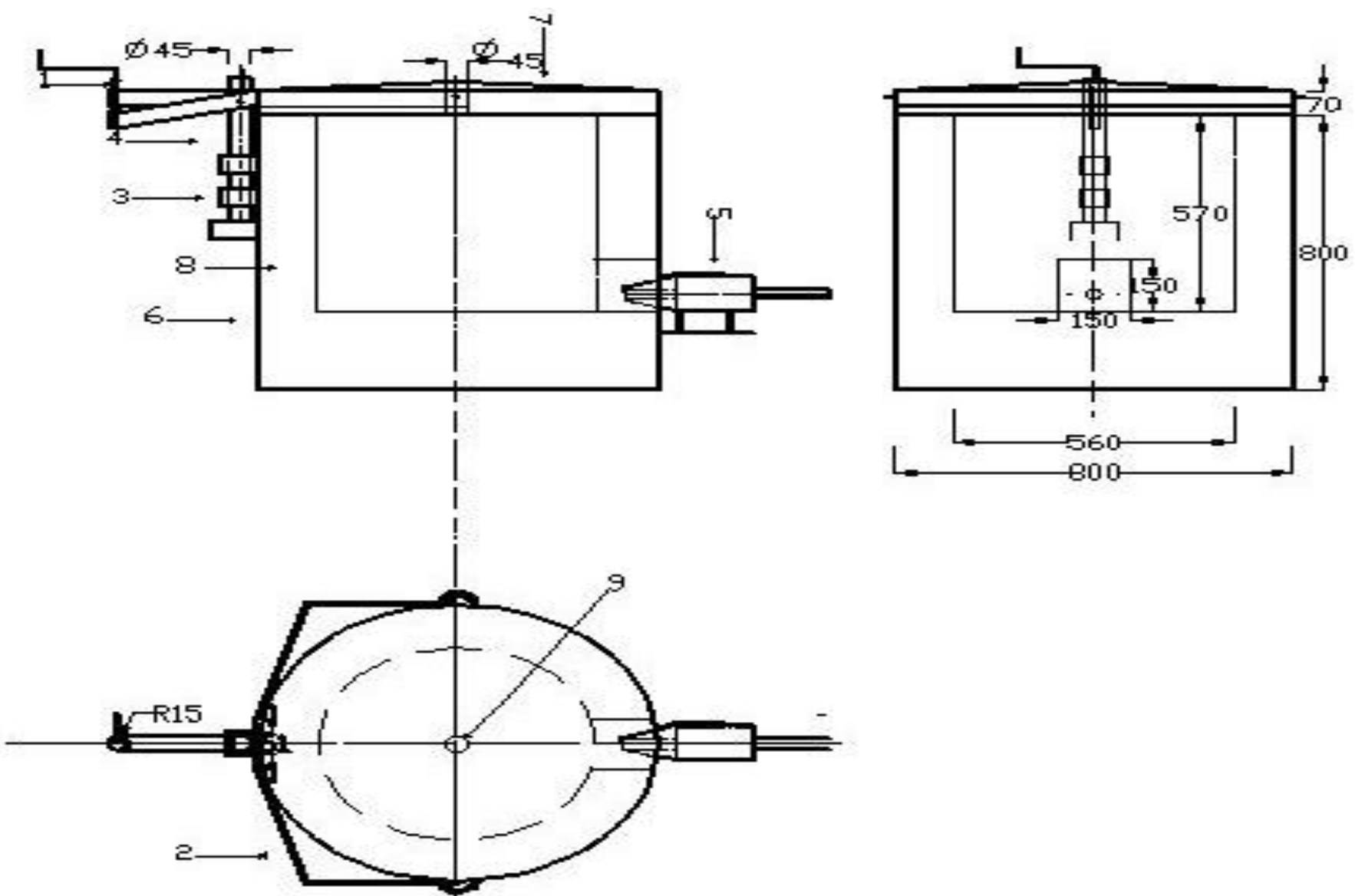

Fig 9: First Angle Orthographic Projection of the Furnace 
Table 1: Part List of The Cast-Iron crucible Furnace

\begin{tabular}{|l|l|}
\hline S/N & Items \\
\hline 1 & Threaded rod \\
\hline 2 & Cover hanger \\
\hline 3 & Bearing \\
\hline 4 & 5 mm diameter Mild steel rod \\
\hline 5 & Burner nozzle \\
\hline 6 & Furnace drum \\
\hline 7 & Furnace cover \\
\hline 8 & Brick lining \\
\hline 9 & Chimney \\
\hline
\end{tabular}

\section{WORKING PRINCIPLE OF THE CRUCIBLE}

\section{FURNACE}

The furnace is first and foremost preheated before firing it by igniting combustible materials such as coal in the combustible chamber. While the coal is still burning the valves that control the supply of diesel fuel on the diesel fuel supply pipe and air from the air blower through the nozzle respectively are slightly opened to allow in drops of fuel and air under pressure. The air is blown over the fuel to atomize as well as oxidize it for combustion. As the mixture of air and fuel blows over the pre-lit coal it helps to sustain the combustion. As this continues over time, the temperature rises gradually within and around the crucible, thereby melting its content.

The furnace temperature can be read directly from an optical pyrometer through the chimney on the cover. When the crucible content is fully melted and is ready for pouring, the crucible is lifted out by means of a lifting tong, which is handled by two persons and then poured into the prepared mould cavity. The holes on the sides of the furnace are made to keep a balance between the pressure within and outside the system.

\subsection{Regulation of the Furnace Temperature}

The temperature of the furnace can be regulated by simply controlling the air/fuel mixture content. It is done by opening or closing slightly the control valves of either or both of air and diesel fuel, to regulate the air-fuel ratio or the amount of air and diesel fuel entering the combustion chamber. The furnace temperature can be determined during melting operations by various means such as; focusing the pyrometer on the flame from the furnace through the chimney provided at the top of the cover and the temperature is read directly. Secondly through incorporation of a thermocouple in the furnace designed to enable the temperature of the metal during melting to be monitored. A traditional method which is not safe is by dipping a long iron rod into the molten metal to check if it has completely melted.

\section{DESIGN ANALYSIS}

\subsection{Design Analysis of the Furnace Drum}

The furnace drum was made from a $5 \mathrm{~mm}$ thick mild steel plate rolled into a cylinder of diameter of $800 \mathrm{~mm}$ and height
$800 \mathrm{~mm}$ with the overall combustion space of diameter $560 \mathrm{~mm}$ and height $570 \mathrm{~mm}$.

The Detailed dimensions of the furnace drum are as follows: (i) Height of the furnace drum before laying bricks (h) = $800 \mathrm{~mm}$

(ii) Height of combustible space of the furnace drum after laying of bricks $\left(\mathrm{h}_{1}\right)=570 \mathrm{~mm}$

(iii) Internal diameter of the furnace drum before laying of bricks $(\mathrm{d})=790 \mathrm{~mm}$

(iv) Internal diameter of the furnace drum after laying of bricks $\left(\mathrm{d}_{1}\right)=560 \mathrm{~mm}$

(v) Inlet diameter of the burner nozzle $=102 \mathrm{~mm}$

(vi) Outlet diameter of the burner nozzle $=35 \mathrm{~mm}$

(vii) Height of the cover $=90 \mathrm{~mm}$

(viii) Total height of the drum = height of drum + height of cover $=800+90=890 \mathrm{~mm}$.

(ix) Diameter of the chimney hole (on cover) $=60 \mathrm{~mm}$

(x) Thickness of the metal plate $=5 \mathrm{~mm}$

Therefore Combustible Volume of furnace after laying of bricks $=\mathrm{V}_{1}=\frac{\pi d_{1}^{2} h_{1}}{4}=\frac{3.142 \times 560^{2} \times 570}{4}$

$$
\stackrel{4}{=} 140409696 \mathrm{~mm}^{3}=0.1404 \mathrm{~m}^{3}
$$

\subsection{Design Analysis of the Air Blower}

The air blower is rated as follows;

Outlet pressure $=1700 \mathrm{~Pa}$, (from blower)

Speed $=2850 \mathrm{rpm}$

Power $=0.55 \mathrm{KW}$

Voltage $=220 \mathrm{~V}$

Current $=2.5$ Amperes

Average rate of air flow from blower $=18 \mathrm{~m}^{3} / \mathrm{min}$

Average rate of fuel flow $=0.045 \mathrm{~m}^{3} / \mathrm{min}$

Ratio of air discharge to fuel discharge $=18 / 0.45=400: 1$

\section{Note:}

The reduced area of the nozzle outlet further increases the air pressure at the nozzle end. The increased air pressure at the blower outlet helps to atomize the fuel for efficient combustion to be achieved.

\subsection{Design Analysis for Efficiency of the Furnace}

The efficiency of the furnace is the ratio of the heat input to useful output. To calculate the furnace efficiency, we divide the theoretical amount of heat needed by actual amount of heat used to melt a specific amount of metal.

$$
\text { i.e. Efficiency }=\frac{\text { Heat Input }}{\text { Heat Output }} \times 100 \%
$$

The efficiency of crucible furnaces range from a low $3.5 \%$ to a high $28 \%$, the common commercial average being around $15 \%$.

The efficiency of the crucible furnace when melting cast iron is calculated as follows:

Mass of metal (cast iron) $=50 \mathrm{Kg}$ 
Theoretical energy content to melt $50 \mathrm{~kg}$ of cast iron at $1400^{\circ} \mathrm{C}\left(2552^{\circ} \mathrm{F}\right)$ when its original temperature at STP is $15^{\circ} \mathrm{C}\left(60^{\circ} \mathrm{F}\right)$, is calculated below.

From properties of materials table, $\left({ }^{*} 1 \mathrm{kj} / \mathrm{kg} . \mathrm{K}=1 \mathrm{kj} / \mathrm{kg}{ }^{0} \mathrm{C}\right)$

Specific heat of cast iron $($ solid $)=0.46 \mathrm{kj} / \mathrm{kg}$. K

Specific heat of cast iron (liquid) $=0.349 \mathrm{kj} / \mathrm{kg}$. K

Heat of fusion of cast iron $=126 \mathrm{kj} / \mathrm{kg}$

Melting point of cast iron $=1200^{\circ} \mathrm{C}$

Temperature rise, up to melting point $=1200-15=1185^{\circ} \mathrm{C}$

Energy content required to raise temperature of metal (cast iron) to melting point $=$ weight $\mathrm{x}$ specific heat $($ solid $) \mathrm{x}$ temperature rise.

$$
=50 \times 0.46 \times 1185=27255 \mathrm{kj}
$$

Now energy content required to superheat metal to $1400^{\circ} \mathrm{C}=$ weight $\mathrm{x}$ specific heat (liquid) $\mathrm{x}$ temperature rise

$$
=50 \times 0.349 \times(1400-1200)=3490 \mathrm{kj}
$$

Total energy content of cast iron $=27255+3490+126$

$$
=30871 \mathrm{kj} / \mathrm{kg} . \mathrm{K}
$$

The total amount of energy consumed in the furnace is calculated by multiplying the number of liters of fuel by the energy content per litre of fuel.

Total Amount of Energy $=$ No. of litres $\mathrm{x}$ energy content per litre

Fuel oil (diesel) is rated at $139000 \mathrm{kj} /$ gallon to melt $50 \mathrm{~kg}$ of metal.

$*($ therefore $139000 / 4.6=30217.39)$

$* 1$ gallon $=4.6$ litres (British unit)

Heat Energy $=9.0$ liters x $30217.39 \mathrm{kj} / \mathrm{kg}$

$=271956.51 \mathrm{Kj} / \mathrm{kg}$

Therefore, the furnace efficiency is calculated thus:

$$
\begin{gathered}
\text { Efficiency }=\frac{\text { Heat Input }}{\text { Useful Output }} \times 100 \%=\frac{30871}{271956.51} \times 100 \%= \\
11.4 \%
\end{gathered}
$$

The efficiency of the furnace increases with increased volume or mass of metal i.e. the higher the melting capacity, the higher the efficiency.

This calculation may be repeated for any type of fuel, furnace or metal.

\section{RESULTS AND DISCUSSION OF RESULTS}

From the results obtained above, the efficiency of the furnace was found to be in the range of $10 \%$ to $12 \%$ showing that most of the heat generated in the furnace was actually used in the melting of the metal.

A crucible furnace of $50 \mathrm{~kg}$ melting capacity has been designed in line with the set objective of the research work. With the design efficiency of about $12 \%$, when compared with the efficiency of $15 \%$ obtainable from the conventional crucible furnace, it can be said to be over $80 \%$ efficient as well as effective, and can conveniently replace the conventional imported crucible furnace in line with the Federal Government import substitution policy in order to

\begin{tabular}{|c|c|c|c|}
\hline Description & Qty & $\begin{array}{l}\text { Unit } \\
\text { Price } \\
\text { N }\end{array}$ & $\begin{array}{l}\text { Total } \\
\text { N }\end{array}$ \\
\hline Plain Bearing & 2 & 2,150 & 4,300 \\
\hline $5 \mathrm{~mm}$ plate & 2 & 24,000 & 48,000 \\
\hline Gate Valves & 2 & 150 & 300 \\
\hline Cutting stone & 6 & 250 & 1,500 \\
\hline Kaolin & 5 bags & 2,500 & 12,500 \\
\hline Sodium Silicate & $\begin{array}{l}4 \\
\text { gallons }\end{array}$ & 2,500 & 10,000 \\
\hline $\begin{array}{l}\text { Electrode (Gauge } \\
12)\end{array}$ & $\begin{array}{l}8 \\
\text { packets }\end{array}$ & 850 & 6,850 \\
\hline Galvanized Pipe $\left(2^{\mathrm{II}}\right)$ & 1 & 5,600 & 5,600 \\
\hline Threaded Red & 1 & 1,500 & 1,500 \\
\hline Flexible Hose & $5 \mathrm{~m}$ & 200 & 1,000 \\
\hline Tape & 1 & 50 & 50 \\
\hline $\begin{array}{l}\text { Refractory Materials } \\
\text { (Bricks) }\end{array}$ & 95 & 1,000 & 95,000 \\
\hline Ball Gauge & 1 & 500 & 500 \\
\hline $\begin{array}{l}\text { Elbow }\left(4^{I I}\right. \\
\text { galvanized elbow })\end{array}$ & 8 & 150 & 1,200 \\
\hline Drawing/printing & & & 11,000 \\
\hline Pipe Wrench & 1 & 800 & 800 \\
\hline $75 \mathrm{~mm}$ diameter Rod & 1 & 4,000 & 4,000 \\
\hline $\begin{array}{ll}45 \mathrm{~mm} & \text { diameter } \\
\text { (threaded) }\end{array}$ & 1 & 3,000 & 3,000 \\
\hline Flat Bar & 2 & 4,200 & 8,400 \\
\hline Cement & 3 & 2,000 & 6,000 \\
\hline Miscellaneous & & & 37,300 \\
\hline Galvanized sheet & 3 & 9,000 & 27,000 \\
\hline Air Blower & 1 & 21,500 & 21,500 \\
\hline Labour & & & 40,500 \\
\hline Total & & & $\begin{array}{l}347,80 \\
0\end{array}$ \\
\hline
\end{tabular}
conserve foreign exchange. Moreover, with design temperature range of $1300^{\circ} \mathrm{C}$ to $1400^{\circ} \mathrm{C}$, cast iron can be conveniently melted using the $50 \mathrm{~kg}$ melting furnace.

Table2: Bill For Engineering Measurement And Evaluation

\section{CONCLUSION}

Finally this research has proved beyond reasonable doubt that, given the right environment and necessary support, local raw materials can be efficiently used to design a heating equipment that can provide the basis upon which our small and medium scale Foundry enterprises can thrive, in order for them to be able to produce spare parts and machine components which hitherto could have been imported from overseas, thereby saving foreign exchange. Its comparative cost advantage when compared with imported ones gives it additional credit. 


\section{RECOMMENDATION}

In order to improve on the design of the crucible furnace, it is recommended that the burner compartment should be made in such a way that it will be adjustable. This will enable the burning zone to be adjusted to suitable positions. The $50 \mathrm{~kg}$ capacity diesel fired crucible furnace is strongly recommended, especially for small Foundry workshops, for melting cast-iron which has meting temperatures lying within the designed range.

\section{ACKNOWLEDGEMENTS}

We wish to thank Mrs Asibeluo Eloho Hope, Mrs Ogwor Dorathy Nkiruka and Mr Emifoniye Elvis for their support to us during the course of this research work.

\section{REFERENCES}

[1]. Asibeluo I.S (2015): Fundametals of Foundry Technology and Forging Operations. Second edition. Published by CEE EMMY VENTURES Agbor, Delta State, Nigeria.

[2]. Adeosun, S.O., Osoba, L.O. (2008):” Foundry Industry; A Tool for Technological Advancement in Nigeria". Proceedings of Nigeria Metallurgical Society Conference. October/November at Federal University of Technology, Akure. Pg. 1.

[3]. Aderibigbe, D.A. (1994): "Foundry Africa '94: Aims and Objectives" Foundry Chronicle, March Foundry Association of Nigeria. Pg.1.

[4]. Aderibigbe, D.A. (1995): "Communique/Seminar Report" Foundry Chronicle May, July Foundry Association of Nigeria Pg. 3-5.

[5]. American Foundrymen Society (1990): "Metal Casting -An Art, A Science, A Career". A.F.S. Des Plaines, Illinoism U.S.A.

[6]. Ezekwe, G.O. (1995): "Foundry is Mother of all Industries" Foundry Chronicle 1(2): 1 January-March Foundry Association of Nigeria.

[7]. Isoun, T.T. (1987): Evolution of Science and Technology in Nigeria, Ibadan University Press, Nigeria P. 12.

[8]. Jain R.K (2009): Production Technology (Manufacturing Process, Technology and Automation). Published by Romesh Chander Khanna for KHANNA PUBLISHERS 2-B, Nath Market, Nai Sarak, Delhi-110006. [9]. Khan, R.H. (1994): "Needs and Strategies for Steel Foundry Development in Nigeria" Proceedings of Nigeria Metallurgical Society, Pp. 44, 48.

[10]. Khurmi R.S. and Gupta J.K.(2005): A Textbook of Machine Design. Printed in India by Rajendra Ravindra Printers (Pvt) L.t.d. 7361, Ram Nagar, New Delhi - 110055 and published by Eurasia publishing House (P) Ltd. Ram Nagar, New Delhi - 110055.

[11]. Nwonwu, G.E.(1991):"Investment Opportunities in Small Scale Foundries". Proceedings of Nigerian Metallurgical Society. Pp. 41-43.

[12]. R.S. Khurmi, J.K. Grupta (2005): Machine DesignFourteenth Edition
[13]. RMRDC (2003): Multi-Disciplinary Committee Report of the "Techno-Economic Survey on Base Metal, Iron \& Steel and Engineering services sectors",

[14]. Ogunrinola, G.O. (2000): "Reassessing Nigeria's Technological Development Strategies" Engineering Conference Proceedings. Kaduna Polytechnic, Kaduna, Nigeria.

[15]. Mukoro, E.E (2009): A Survey of the Foundry Industry In Nigeria. Published by Bamise Printing and Publishing Press, No. 73 Ameh Oboni Street, Sabongari Idah, Kogi State, Nigeria. 